\title{
INVESTIGAÇÃO-AÇÃO EDUCACIONAL E CURRÍCULO
}

\section{Claiton José Grabauska Cléria Maria Wendling}

\section{Nossa concepção de trabalho educativo: vinculando ensino e pesquisa na formação de professores.}

Ao longo de nossa trajetória escolar, seja como educadores, ou como educandos, fomos construindo a compreensão a respeito da necessidade de acoplar investigação e ensino em nossas práticas. Nesta perspectiva, buscamos não dissociar teoria e prática, indivíduo e sociedade. Isto significa, em última instância, reconhecer a dimensão política da educação e agir com a clara intenção de transformá-la, auxiliando nas transformações sociais mais amplas.

Estes dois aspectos - a dimensão política e a intencionalidade emancipatória - colocam a possibilidade de tornar os professores, mediados pela investigação das suas práticas pedagógicas, profissionais com mais poder - "empowerment". Neste sentido, a concepção que permite realizar estas metas, ao nosso ver, é a investigaçãoação educacional emancipatória (conforme Carr e Kemmis, 1986). Esta noção encontra paralelos com o que foi expresso por Freire:

\begin{abstract}
A pedagogia do oprimido, como pedagogia humanista e libertadora, terá dois momentos distintos. O primeiro, em que os oprimidos vão desvelando o mundo da opressão e vão comprometendo-se na práxis, com a sua transformação; o segundo, em que, transformada a realidade opressora, esta pedagogia deixa de ser do oprimido e passa a ser a pedagogia dos homens em processo de permanente libertação (1981:44).
\end{abstract}

Assim como na investigação-ação, importantíssimo no processo de transformação da realidade, ou na libertação, para utilizar a conceitualização freireana, é o papel desempenhado pelos sujeitos em sua prática social. Prática que não deve ser confundida com ativismo, mas que deve servir de guia para o conhecimento e possível transformação da realidade. Desta forma, a partir de sua prática como educador, Freire vai traçar um dos princípios básicos de uma concepção educacional libertadora, a qual iria subsidiar a investigação-ação: "Foi nesta prática de mais de dez anos que ele [Freire] aprendeu a ser educador e desvelou um princípio básico de sua teoria e prática educacional, ao qual permaneceu fiel - 'pensar sempre 
na prática'" (Costa, 1991:48). Costa, também, destaca duas obras de Freire como exercendo papel importante no redimensionamento da investigação-ação:

Este primeiro livro [EDUCAÇÃO COMO PRÁTICA DA LIBERDADE], que depois é seguido pela obra PEDAGOGIA DO OPRIMIDO, repercute no Estados Unidos e na Europa e, de certa forma, inaugura o caráter políticoemancipatório com que a pesquisa-ação em educação passa a ser utilizada em vários países (Costa, 1991:48).

É importante ressaltar a centralidade da noção de diálogo no pensamento de Freire. Diálogo que tem como premissa o conhecimento sobre o objeto em questão; não é possível, desta forma, dialogar sobre o que não se conhece, o que configura invasão cultural:

Não fazemos esta afirmação ingenuamente. Já temos afirmado que a educação reflete a estrutura do Poder, daí a dificuldade que tem um educador dialógico de atuar coerentemente numa estrutura que nega o diálogo. Algo fundamental, porém, pode ser feito: dialogar sobre a negação do próprio diálogo (Freire, 1981:71; rodapé).

É objetivo da investigação-ação o compartilhamento de decisões, de responsabilidade, de poder, portanto. Mesmo que se questione o quanto este poder de decisão possa ser compartilhado, é válido afirmar que os sujeitos, na esfera de um projeto de investigação-ação, são, efetivamente, desafiados a exercê-lo. Os porquês de uma divisão não "igualitária" deste poder serão explorados mais adiante, quando trataremos da deliberação curricular. Mas, para um educador comprometido com a transformação, o diálogo é um princípio (tanto no sentido de início de uma caminhada investigativa colaborativa, como no sentido epistemológico), o qual pode alavancar as autocompreensões dos sujeitos envolvidos nas práticas.

Realmente, Freire (1981) coloca uma questão totalmente original a respeito da prática educativa; não como algo a ser "doado" por quem sabe a quem não sabe; mas, sim, como uma forma de os seres humanos se apropriarem, conscientemente, de sua realidade para, assim, terem condições de transformá-la.

A necessidade de que o educador-educando se coloque como um investigador também é um aspecto que reforça uma mudança na própria epistemologia do conhecimento pedagógico, descentrando o ato educativo ou, mais do que isto, procurando torná-lo um ato de comunicação em comunhão, onde os homens, em conjunto, constroem seu conhecimento e, por sua práxis, podem lutar para "Ser Mais". 
Esta preocupação começa a se delinear, também, em Elliott (1978), que localiza a investigação-ação como uma maneira viável de gerar novos conhecimentos a partir da compreensão que os sujeitos (no caso, os professores) têm de sua situação, refletindo sobre ela, com a finalidade de transformá-la.

Neste sentido, Elliott destaca a importância, na investigação-ação, da noção de diálogo como ferramenta constitutiva do processo de pesquisa, a "imersão" do pesquisador na realidade dos participantes, bem como a rede de acordos éticos que deve haver entre os sujeitos que vivem o processo:

Os participantes devem ter livre acesso aos dados, interpretações e apontamentos do pesquisador, e 'o pesquisador' deve ter livre acesso a 'o que está acontecendo' e sobre as interpretações que os participantes têm disso. Por isto que a pesquisa-ação não pode se estabelecer adequadamente na ausência da confiança, estabelecida pela fidelidade a uma rede ética mutuamente pactuada, a qual governa a coleta, o uso e a difusão dos dados (Elliot, 1978:357).

A partir destes pressupostos, a investigação-ação, incorporando algumas das concepções de Freire $(1981,1983)$, inscreve-se em uma nova dimensão, nitidamente interessada na emancipação dos seres humanos e francamente favorável à transformação da realidade.

No entanto, esta vertente parece não se firmar como dominante ou exclusiva no campo da investigação-ação, como alerta Carr (1989). Por um lado, a investigaçãoação é utilizada como mero instrumento de resolução de problemas da prática, sem conseguir constituir um corpo teórico mais radicalmente oposto ao positivismo. Esta maneira de interpretar a investigação-ação, em última instância, descaracteriza-a como concepção alternativa de investigação ao positivismo. Por outro lado, existe a manifesta preocupação de que ela se constitua claramente em concepção, e não, apenas, em um modo de operar a investigação. Para tanto, Carr destaca, por exemplo, o autoconhecimento reflexivamente adquirido como categoria epistemológica, apesar da objetificação da realidade, dominante na ciência atual, em função do domínio positivista:

Uma medida da extensão em que o positivismo atingiu sua intenção é seu sucesso em negar o autoconhecimento reflexivamente adquirido como uma categoria epistemológica válida. Outro é seu sucesso em excluir todas aquelas formas de teorização social e educacional que recusam se autoconfinar na experiência 'como ela é', mas, ao invés disto, insistem que a experiência é sempre condicionada por interpretações filosóficas e compreensão histórica. (Carr, 1989: 88). 
No sentido de quebrar a dicotomia entre especialistas e "praticantes" (professores), Carr e Kemmis (1986) vão adiante, ao apontar as potencialidades da investigação-ação, não esquecendo, porém, de mostrar seus limites caso seja pensada dentro da racionalidade positivista. Neste sentido, ela pode não ultrapassar o mero ativismo.

Se, porém, for concebida num contexto que leve em conta as determinações históricas e os decorrentes vieses filosóficos (que procuram justificar, ou obscurecer, as primeiras), a investigação-ação estará se constituindo em uma concepção de investigação ancorada na racionalidade emancipatória. Desta forma, poderá realizar aqueles ideais de liberdade de pensamento e de ação a partir das leituras que os sujeitos fazem de sua própria realidade.

Assim planejada e praticada, a investigação-ação, como concepção de pesquisa, pode auxiliar os seres humanos a interpretar a realidade a partir de suas próprias práticas, concepções e valores. Aí está um potencial transformador bastante grande. Caso contrário, estará se repetindo o mesmo erro do passado, ao se deixar que outros, as classes dirigentes, façam as leituras do mundo e as transmitam como sendo a verdade.

Assim, nossas práticas educativas têm-se pautado por procurar compartilhar as ações nos espaços em que agimos e interagimos, constituindo comunidades de investigadores a partir do referencial da investigação-ação emancipatória.

Neste sentido, cabe a crítica aos cursos de licenciaturas pela dissociação dos espaços da elaboração curricular e da ação educativa, como se o simples acúmulo de teorias educacionais, metodologias do ensino e conteúdos específicos, sobrepostos posteriormente, pudesse assegurar uma "boa" prática profissional.

Assim, durante a formação inicial, tem-se um estudante que vive o "verbo" da profissão de professor; quando vai atuar, já como profissional, passa ao ativismo, com práticas intuitivas, mesclando fragmentos do conhecimento educacional que deveria ter dominado na graduação. Portanto, acaba promovendo, mesmo que não perceba, uma espécie de ativismo, por afirmar a "prática" ou a "experiência" como suficiente para a ação docente - esquecendo-se do próprio discurso do professor como um ser que nunca está "formado", sempre tem a aprender. No entanto, justamente porque foi apenas discurso, e não uma conduta profissional apreendida ao longo da formação 
teórico-prática, acaba como apenas um corolário para obscurecer o ativismo que não quer enxergar a necessidade da teoria que pode informar a prática.

Ao se reconhecer a mútua determinação entre teoria e prática, pode-se contribuir para efetivar o projeto de libertação, nos planos da ação e da reflexão, a partir das visões de mundo que os sujeitos têm de sua própria realidade vivida. Desta forma, planejada, vivida, auto-refletida e refletida colaborativamente, a investigaçãoação educacional, como concepção de investigação científica, pode tornar-se potencializadora de novas ações para os seres humanos, a partir de suas vivências, práticas, concepções e valores. Aí reside um potencial transformador bastante grande, frente a uma realidade educacional como a brasileira.

Desta forma, a consideração de uma diferença no status de investigadores e participantes carrega em si a perpetuação de uma situação de opressão. É necessário ultrapassar esta dicotomia para vivenciar a investigação-ação numa concepção emancipadora. Para tanto, o diálogo constitui-se como elemento fundamental, que pode romper esta relação hierárquica e dominadora (por exemplo, Freire,1981).

\section{Um exemplo de nossa prática: investigando com os sujeitos...}

Uma das nossas ações é realizada na comunidade educativa de Iporã do Oeste/ SC, sendo composta por professores do ensino fundamental, em sua maioria atuando nas séries iniciais, direção da escola e secretaria do município. Tal comunidade abrange a escola municipal localizada na cidade e as escolas isoladas do interior.

O primeiro contato deu-se nas reuniões de planejamento geral para o ano letivo de 2002, na qual apresentamos uma proposta de realizar o projeto de mestrado junto com os sujeitos desta comunidade. Apresentamos a proposta de investigar as próprias práticas na concepção da investigação-ação educacional. Com a boa aceitação da proposta e o comprometimento dos sujeitos com as atividades que esta pesquisa iria desenvolver junto com eles, iniciamos as atividades.

A investigação-ação, composta por ciclos de planejamento, ação, observação e reflexão para um novo planejamento, organiza as práticas investigativas em uma espiral, na qual cada ciclo aumenta a autocompreensão dos sujeitos sobre a situação vivida, tencionando melhorar as práticas realizadas. As atividades de ensino servem 
de elemento para observação e a reflexão. O primeiro ciclo foi realizado com professores que atuam nas escolas isoladas.

O planejamento do primeiro ciclo tinha o objetivo de resolver problemas diagnosticados nas interações iniciais com os alunos. Um problema levantado foi a falta de higiene de corpo, problema geral da turma. Assim, realizamos uma atividade que viesse a problematizar e modificar essa situação. Para tanto, realizamos colaborativamente -- a professora da turma, um professor de outra escola isolada que faz seu planejamento no mesmo dia, e nós - uma atividade dentro da abordagem metodológica dos três momentos pedagógicos (Delizoicov e Angotti, 1990). Estes momentos pedagógicos servem como estratégia didática para organizar a etapa da ação no ciclo antes mencionado.

Para o primeiro momento, correspondente à problematização inicial, organizamos uma experiência com meio de cultura para as bactérias, acrescentando a diferentes recipientes, água de torneira, de rio, empoçada e água onde foram lavadas as mãos dos alunos.

Esses meios de cultura foram observados por uma semana, sendo que 0 desenvolvimento de fungos e bactérias foi maior último pote, com a água das mãos. $\mathrm{Na}$ realização da experiência e no decorrer das observações, os alunos eram questionados, buscando levantar seus conhecimentos prévios. Para o segundo momento, -- organização do conhecimento - foram utilizados textos retirados de diversas fontes, inclusive de livros didáticos, sobre higiene e receitas para o controle de piolhos pesquisados com os pais dos alunos. No terceiro momento -- aplicação do conhecimento -- propôs-se a produção de textos que viessem a possibilitar a verificação sobre as mudanças conceituais que a atividade ocasionou.

Essa atividade foi realizada durante três semanas, sendo que foram trabalhados conteúdos de matemática, como a pesquisa de preço dos materiais de higiene, etc. assim como português, e demais conteúdos do programa curricular.

A professora foi registrando sua observação e sua auto-reflexão, no decorrer da atividade, que serviram de subsídio para reflexão do grupo. No grupo a atividade foi avaliada, procurando as possibilidades de melhoras e os pontos positivos do trabalho, sendo que, ainda, encaminhou o próximo planejamento para a temática 
referente à água. Este planejamento constitui, desta forma, o início do segundo ciclo da espiral antes referida.

\section{O currículo como campo de contestação, de construção e de desenvolvimento profissional.}

A deliberação curricular está intrinsecamente relacionada à conjuntura social e às relações de poder nela existentes. A educação tem sido, no decorrer dos tempos, uma "ferramenta", tanto para a transformação como para o controle e manutenção social. Pensando assim, poderíamos assinalar esse processo configurado numa relação conflituosa entre os que defendem o projeto atual e os que buscam sua superação. Os conflitos são, muitas vezes, dominados por um discurso de consenso, imposto pela hegemonia. Os sujeitos que elaboram e determinam os currículos, estão defendendo os interesses da classe social (classe hegemônica), que por sua vez, delegou-Ihes esse poder.

O projeto da hegemonia, que, segundo Apple (1994), é defendido pela Direita Tradicional, vem conduzindo as políticas de determinação curricular em dimensões internacionais e nacionais, que se refletem diretamente nas práticas locais. Historicamente, a educação brasileira vem determinada por alguns mecanismos de homogeneização do trabalho educativo. Nesse sentido, os livros didáticos são mecanismos importantes na homogeneização de conceitos, conteúdos e metodologias educacionais (ainda mais agora, em que muitos recebem a chancela do MEC, por intermédio dos Parâmetros Curriculares Nacionais...). E, também, por serem estes materiais os principais norteadores das práticas de muitos professores. Como praticamente não diferem nas distintas edições e editoras, os livros sugerem um conhecimento oficial, o dito corpus formal dos conteúdos curriculares, que nega as construções do conhecimento, da realidade cultural concreta dos sujeitos e a realidade dos conflitos sociais. Vejamos:

No campo da educação pública há evidências de que a crescente centralização da publicação de livros didáticos em mãos de umas poucas grandes corporações multinacionais tem significado que esses livros se tornaram mais homogeneizados, e que excluem, seletivamente, tópicos ou perspectivas que poderiam despertar controvérsias. (Dennis \& Apple, 2000; 37-38) 
Juntamente com a divulgação de livros didáticos que homogeneízam e legitimam certa cultura e conhecimento, as ideologias de mercado são consolidadas e apoiadas por políticas globais, impondo uma série de valores e condutas, orientadas, de um lado, pelo neoconservadorismo e por outro pelo neoliberalismo.

Na perspectiva do neoliberalismo, a economia é regida pela livre competição, minimizado o poder do Estado sobre a esfera econômica. Já o neoconservadorismo zela por um estado forte, na sua função de controle social, determinando e incutindo valores para conter os excessos do mercado, minimizando as possíveis revoltas sociais. Valores estes, marcados pelo individualismo e competitividade.

Essas duas correntes da direita conservadora carregam concepções que aparentemente são contraditórias, mas, que de fato se complementam. O neoconservadorismo busca o fortalecimento do Estado na sua função de controle social e o neoliberalismo busca a minimiza da ação do estado, deixando o controle econômico nas mãos do livre comércio. Seus interesses concentram-se muito pouco voltados à melhoria das oportunidades de vida das mulheres, das pessoas negras ou da classe trabalhadora, por exemplo. Em vez disso, estão empenhados em promover as condições educacionais tidas como necessárias para não só aumentar a competitividade internacional, o lucro e a disciplina, mas também para resgatar um passado romantizado de lar, família e escolas "ideais". (Apple,1994; 68).

Após a segunda guerra, os EUA entraram numa era de industrialização e os valores como cooperação e especialização, provindos do mundo industrial, passaram a ser aceitos e difundidos. A escola passa, assim, a contribuir para a expansão desses novos valores. Os estudos do novo campo (o currículo) estão vinculados ao propósito de propagar, entre as novas gerações, os valores, as condutas e os hábitos adequados para a época. Dessa forma, o currículo passa a ser um importante meio de controle social, sendo a estas conferidas características de ordem, de racionalidade técnica e de eficiência.

Assim como nos EUA, no Brasil os currículos escolares também fazem parte de um mecanismo poderoso de determinação educacional, atendendo interesses da sociedade industrial. Na década de 60 , os currículos brasileiros passam a receber uma determinação curricular internacional. Nessa tendência, os currículos e planos educacionais eram elaborados por um grupo de especialistas com interferência direta do USAID (Agência para o Desenvolvimento Internacional - Estados Unidos) e do 
Banco Mundial, iniciando, deste modo, a política de "intromissão" internacional sobre a educação brasileira, atuando fortemente através dos currículos pré-determinados.

Cabia ao professor, neste período, executar as tarefas determinadas e controladas pelos especialistas elaboradores dos currículos. O controle feito pelo tecnicismo foi explícito e extremista, sob o discurso de estar atendendo a demanda social dos avanços industriais para a formação de mão-de-obra técnica.

Nas tendências educacionais posteriores, o currículo esteve de certa maneira a mando de sujeitos alheios ao processo para o qual é destinado, direta ou indiretamente. Atualmente podemos ver nos Parâmetros Curriculares Nacionais e no uso dos livros didáticos por eles "legitimados" uma forma eficaz de controle curricular, uma vez que estes fornecem aos professores a metodologia, os conteúdos, e até mesmo os critérios de avaliação "adequados" para o ensino. E como este material é distribuído gratuitamente nas escolas, se torna o maior recurso para os professores. Ou até mesmo o único material de pesquisa para planejamento das atividades educacionais.

Nas práticas atuais e presentes nos espaços onde temos atuado como investigadores, ou seja, escolas municipais do ensino fundamental, isto também acontece, embora em proporções menores. Os livros didáticos são, também, os materiais de pesquisa utilizados pelos professores para o planejamento das atividades. Nestes são buscados textos para o trabalho com o conteúdo sistematizado, que, muitas vezes, não apresentam o mínimo de profundidade exigido para o acesso aos conhecimentos pelos estudantes.

Essa realidade, no entanto, vem mudando, como se pode perceber pelo relato da seção anterior, com a prática dos dias destinados aos planejamentos. Neste espaço de tempo, vem sendo possível a reflexão crítica sobre as orientações dos livros, seguindo para uma ação deliberativa, por parte dos professores, frente às suas práticas.

Nos momentos em que podemos estar presentes nos planejamentos, construímos um espaço de discussão crítica deliberativa, buscando outras fontes de matérias, como textos tirados da rede, outros elaborados pelos pelo próprio grupo depois da realização de pesquisas. Nesses momentos, também discutimos e planejamos o encaminhamento das aulas. Procuramos construir uma prática 
problematizadora. As contribuições, mediadas pelo diálogo, vêm legitimando esses momentos na prática educativa do professor. Dessa maneira, temos planejado e realizado algumas práticas que se preocupam com os conhecimentos prévios dos alunos, com a sistematização dos conhecimentos cientificamente elaborados de maneira mais aprofundada e significativa, respondendo aos problemas levantados pelos próprios alunos, e uma avaliação processual. Em alguma medida, começamos uma trajetória de mudança curricular, calcada no diálogo e na deliberação, ao mesmo tempo em que existe o desenvolvimento profissional.

É verdade que estamos iniciando as atividades nesta realidade, mas já é possível verificar que essa maneira de conduzir o processo vem trazendo um melhor resultado nas práticas. As reflexões feitas pelos próprios professores sobre estas práticas demonstram como o planejamento coletivo gera autonomia frente aos livros didáticos e um planejamento mais próximo das necessidades dos alunos.

\begin{abstract}
Uma vez embarcados no processo cooperativo de crítica da ideologia, "cartografando" nossas idéias, práticas e situações em termos de sua história, das relações sociais que ativam e das conseqüências que produzem, a elaboração da teoria crítica do currículo requer que colaboremos na luta política para superar a irracionalidade, a injustiça e a coerção em nosso próprio trabalho e, através do nosso trabalho, na sociedade em seu conjunto (Kemmis, 1988: 136, grifos nossos).
\end{abstract}

A dinâmica de reflexão crítica no planejamento tornou-se viável com a formação de grupos no planejamento, pois foi possível perceber que em outros grupos nos quais não atuamos efetivamente também houve deliberação sobre a prática. Segundo Freire:

Somente os seres que podem refletir sobre sua própria limitação são capazes de libertar-se desde, porém, que sua reflexão não se perca numa vaguidade descomprometida, mas se dê no exercício da ação transformadora da realidade condicionante. Desta forma, consciência de e ação sobre a realidade são inseparáveis constituintes do ato transformador pelo qual homens e mulheres se fazem seres de relações (Freire, 1982: 66).

Amarrar, portanto, a deliberação ou, neste caso, a imposição curricular com livros didáticos e pacotes curriculares nacionais, é primeiramente roubar esse importante componente da ação do profissional da educação. A possibilidade de deliberar as próprias ações partindo das reflexões comprometidas com transformação é próprio da ação educativa. O currículo deve, portanto, ser construído na comunidade educativa, atendendo aos interesses da comunidade específica e ao projeto dos 
sujeitos. Somente assim será possível pensar numa educação democrática voltada para a qualidade de vida e a humanização da sociedade como um todo.

\title{
4. Investigação-ação: desvelando a ideologia dominante na elaboração do currículo
}

Por meio da educação dialógica freireana e da investigação-ação educacional emancipatória, procuramos nosso desenvolvimento profissional (num movimento que podemos chamar de educação contínua) e a autonomia em termos de elaboração curricular. Ao mesmo tempo, buscamos compartilhar esta visão com outros sujeitos, nas esferas em que atuamos colaborativamente (escolas básicas, movimentos de educação de jovens e adultos, práticas de educação não-formal, etc.). Desta maneira, esperamos construir "ferramentas" intelectuais e práticas para escapar dos pacotes curriculares (às vezes, meramente instrucionais) impostos desde as esferas regulamentadoras da educação. Para tanto, é necessário um movimento que acople a ação à teoria:

\begin{abstract}
A forma de proceder não consiste em melhorar o debate educativo e depois melhorar a educação... isto está entrelaçado. Podemos começar fazendo investigações modestas e relevantes na prática em nossos próprios marcos, e desenvolver nossas críticas da escolarização através das críticas de nossas próprias escolas e de suas relações com suas comunidades. Este é o enfoque da investigação cooperativa da ação emancipadora. É também o enfoque descrito como 'investigação crítica' (Kemmis, 1988: 148).
\end{abstract}

Assim, investigando durante a ação educativa, na perspectiva de tornar mais claros os elos entre nossas crenças profissionais e nossa atuação, vamos nos tornando mais autoconscientes a respeito das situações em que estamos inseridos, fundamentados por uma visão e uma compreensão crítica do que-fazer educativo. Nas palavras de Kemmis (1988:154), "a teoria crítica do currículo coloca os participantes do processo educativo no centro deste conjunto de relações, não simplesmente como objeto de análises, mas sim como sujeitos cognoscentes, ativos, não só como produtos da história educativa, mas também como seus agentes".

Procuramos, desta maneira, "restaurar o sentido problemático do currículo para os professores" (Kemmis, 1988: 126), na perspectiva dialógica freireana, visando à emancipação dos sujeitos da irracionalidade e da injustiça das práticas sociais que desumanizam e, muitas vezes, impedem a emancipação/libertação dos seres 
humanos. Neste sentido, a investigação-ação pode contribuir para incrementar o conhecimento pessoal e profissional dos professores, tornando-os mais capazes de enxergar as determinações que sofrem suas práticas. Assim, proporcionando rupturas com o pensamento hegemônico nas sociedades atuais, pois "a burocracia paralisante tem maiores efeitos quando a equipe de professores está mais intelectualmente desarmada" (Gimeno, 1998: 352).

Por isto, nossa opção por trabalhar pela via da investigação. Não se trata de fazer uma investigação sobre os professores, mas com eles, já que "a investigaçãoação é uma forma de indagação introspectiva, coletiva, empreendida por participantes em situações sociais com o objetivo de melhorar a racionalidade e a justiça de suas práticas sociais ou educativas, assim como sua compreensão dessas práticas e das situações em que estas têm lugar" (Kemmis e MacTaggart, 1988:09).

Neste sentido, buscamos maior autonomia profissional, maior poder na elaboração do trabalho educativo e, em última instância, auxiliar, mesmo que de forma modesta, a melhorar as práticas educativas e a sociedade, promovendo a libertação, nossa e daqueles com quem compartilhamos os saberes e práticas.

\section{BIBLIOGRAFIA}

APPLE, M. W. A política do conhecimento Oficial: faz sentida a idéia de um currículo nacional? In Currículo, Cultura e Sociedade, MOREIRA, A. F. B. e SILVA, T. T. (orgs.). São Paulo, Cortez 1994.

APPLE, M. Ideologia e Currículo. SP: Brasiliense, 1982.

COSTA, M. C. V. A caminho de uma investigação-ação crítica. Educação e Realidade, v.16, n. 2, Porto Alegre, dez/1991.

DELIZOICOV, D. \& ANGOTTI, J. A. P. Metodologia do Ensino de

Ciências. Cortez, São Paulo, 1990.

ELLIOT, J. What is Action-Research in Schools? Journal of Curriculum Studies, v. 10, n.4: 355-57, 1978.

FREIRE, P. Pedagogia do Oprimido. 10 Ed. Rio de Janeiro, Paz e Terra, 1981.

FREIRE, P. Ação cultural para a liberdade. $6^{a}$ ed. Rio de Janeiro, Paz e Terra, 1982. 
FREIRE, P. Pedagogia da Autonomia. Saberes necessários à prática educativa. 6. Ed. Rio de Janeiro, Paz e Terra, 1996.

GIMENO SACRISTÁN, J. Curriculum Deregulating Practices: towards the loss of educational sense. Londres, Curriculum Studies, V. 5, n. 3, 1997: 343-68.

GRABAUSKA, C. J. Investigação-Ação na Formação de Profissionais da Educação: redimensionando as atividades curriculares de ciências naturais no curso de Pedagogia. Tese de Doutorado. Universidade Federal de Santa Maria, Centro de Educação, Programa de Pós-Graduação em Educação, 1999.

HYPÓLITO, A. M. \& GANDIN, D. A. (orgs.). Educação em tempos de incertezas. Belo Horizonte, Autêntica, 2000.

KEMMIS, S. El Curriculum: más allá de la teoría de la reproducción. Madrid, Morata, 1988.

KEMMIS, S. La Formación del profesor y la creación y extensión de comunidades críticas de profesores. Investigación en la Escuela, n. 19, 1993: 1538.

KEMMIS, S. e MACTAGGART, R. Cómo planificar la investigaciónacción. Barcelona, Laertes, 1988. 